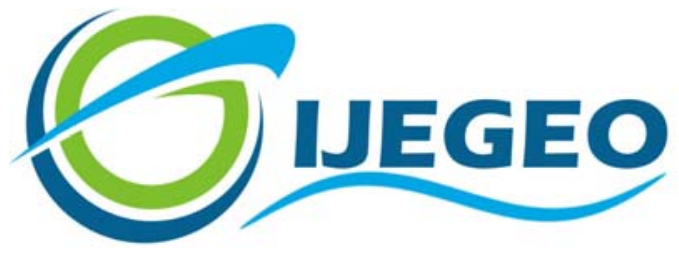

International Journal of Environment and Geoinformatics (IJEGEO) is an international, multidisciplinary, peer reviewed, open access journal.

\section{Interpreting Temperature Based Discontinuity and Roughness of Rock}

\section{Surfaces by Using Photogrammetric Technique}

\author{
Abdullah Harun İncekara, Dursun Zafer Şeker, Celil Serhan Tezcan, \\ Erkan Bozkurtoğlu and Cem Gazioğlu
}

\section{Editors}

Prof. Dr. Cem Gazioğlu, Prof. Dr. Dursun Zafer Şeker, Prof. Dr. Ayşegül Tanık, Assoc. Prof. Dr. Şinasi Kaya

\section{Scientific Committee}

Assoc. Prof. Dr. Hasan Abdullah (BL), Assist. Prof. Dr. Alias Abdulrahman (MAL), Assist. Prof. Dr. Abdullah Aksu, (TR); Prof. Dr. Hasan Atar (TR), Prof. Dr. Lale Balas (TR), Prof. Dr. Levent Bat (TR), Assoc. Prof. Dr. Füsun Balık Şanlı (TR), Prof. Dr. Nuray Balkıs Çağlar (TR), Prof. Dr. Bülent Bayram (TR), Prof. Dr. Şükrü T. Beşiktepe (TR), Dr. Luminita BUGA (RO); Prof. Dr. Z. Selmin Burak (TR), Assoc. Prof. Dr. Gürcan Büyüksalih (TR), Dr. Jadunandan Dash (UK), Assist. Prof. Dr. Volkan Demir (TR), Assoc. Prof. Dr. Hande Demirel (TR), Assoc. Prof. Dr. Nazlı Demirel (TR), Dr. Arta Dilo (NL), Prof. Dr. A. Evren Erginal (TR), Dr. Alessandra Giorgetti (IT); Assoc. Prof. Dr. Murat Gündüz (TR), Prof. Dr. Abdulaziz Güneroğlu (TR); Assoc. Prof. Dr. Kensuke Kawamura (JAPAN), Dr. Manik H. Kalubarme (INDIA); Prof. Dr. Fatmagül Kılıç (TR), Prof. Dr. Ufuk Kocabaş (TR), Prof. Dr. Hakan Kutoğlu (TR), Prof. Dr. Nebiye Musaoğlu (TR), Prof. Dr. Erhan Mutlu (TR), Assist. Prof. Dr. Hakan Öniz (TR), Assoc. Prof. Dr. Hasan Özdemir (TR), Prof. Dr. Haluk Özener (TR); Assoc. Prof. Dr. Barış Salihoğlu (TR), Prof. Dr. Elif Sertel (TR), Prof. Dr. Murat Sezgin (TR), Prof. Dr. Nüket Sivri (TR), Assoc. Prof. Dr. Uğur Şanlı (TR), Assoc. Prof. Dr. Seyfettin Taş (TR), Assoc. Prof. Dr. İ. Noyan Yılmaz (TR), Assist. Prof. Dr. Baki Yokeş (TR), Assist. Prof. Dr. Sibel Zeki (TR), Dr. Hakan Kaya (TR). 


\title{
Interpreting Temperature Based Discontinuity and Roughness of Rock Surfaces by Using Photogrammetric Technique
}

\author{
Abdullah Harun İncekara ${ }^{1,}$ *, Dursun Zafer Şeker ${ }^{2}$, Celil Serhan Tezcan ${ }^{2}$, Erkan Bozkurtoğlu ${ }^{3}$ \\ and Cem Gazioğlu \\ ${ }^{1}$ Gaziosmanpasa University, Faculty of Natural Sciences and Engineering, Department of Geomatics Engineering 60250 Tokat TR \\ ${ }^{2}$ Istanbul Technical University, Faculty of Civil Engineering, Department of Geomatics Engineering 34485 Maslak TR \\ ${ }^{3}$ Istanbul Technical University, Faculty of Mines, Department of Geological Engineering 34485 Maslak TR \\ ${ }^{4}$ Istanbul University, Institute of Marine Sciences and Management, Department of Marine Environment 34134 Fatih TR \\ * Corresponding author \\ Received 20 October 2017 \\ E-mail : abdullah.incekara@gop.edu.tr $\quad$ Accepted 30 December 2017
}

\begin{abstract}
The discontinuity and roughness properties of the rocks can be used to obtain information on surface characterization. In this study, it was investigated whether the discontinuity and roughness properties of the rock structure are related to the temperature of the surface. Selected object which is located at Istanbul Technical University Ayazaga Campus has approximately dimensions of $3 \mathrm{mx} 1 \mathrm{~m}$. The discontinuity regions on the object and the areas which are rougher than their surroundings are clearly identifiable by visual interpretation. 3D model of rock surface was produced by integrating photographs and 12 control points which were homogeneously distributed on the object in order to reflect the surface realistically. The temperature of the control points marked on the surface were measured by using an infrared thermometer with non-contact measuring capability. These values were used as the basic data to show the temperature distribution over the entire surface. Temperature distribution map with 6 classes representing the temperature range was produced by using IDW interpolation method in a commercial GIS software. The temperature distribution map was overlapped on the 3D object model produced by means of RGB photographs for comparison with the 3D model produced by the thermal images of the same surface. The temperature distribution in the discontinuity regions that can be clearly seen as rough was examined and obtained results proved that there is a strong relationship between roughness and temperature of the rock surfaces.
\end{abstract}

Keywords: Interpolation, Photogrammetry, Rock, Roughness, Temperature, Thermal Camera

\section{Introduction}

Surface roughness is one of the most importantparameters governing the shear strength of rock discontinuities which may vary based on genesis, physico-mechanical, and mineralogical properties of rocks (Özvan et al., 2014). The effects of discontinuity surface roughness on the shear strength of weathered granite joints Rock is a mineral mass or a mineral-like solid which consists entirely of a single mineral as well as the accumulation of multiple minerals. A small number of rocks are composed of non-mineral substances like solid organic residues (Ocakoğlu, 2017). Measurements are usually made in contact with the surface in order to determine existing characteristics of the rock such as discontinuity and roughness. The structural disorder and fractures that break the physical connections in the rock structure are called discontinuities (Schultz and Fossen, 2008) and the measure of fluctuations in small scale due to angular changes on the discontinuity surfaces is defined as roughness (Poropat, 2009).
Photogrammetric methods may be preferred in situations where the geological methods may be dangerous and ineffective due to the location of the object. In the photogrammetric method, it is possible to make analyses on the $3 \mathrm{D}$ model produced with the help of photographs to determine and interpret the rock structure properties such as discontinuity, roughness and weathering. The fact that the $3 \mathrm{D}$ model realistically reflects the object is the most important factor that provides this advantage.

In this study, it has been investigated whether the discontinuity and roughness of the rock structures has a relation with the temperature or not. The behaviour of rough surfaces against temperature compared to smooth surfaces has been analyzed. In this way, it has been 
examined that interpreting the rock surface characterization with the help of temperature distribution is possible or not. There are many studies in the literature related to discontinuity and roughness properties of rock structures such as (Anbarasan and Sakthivel, 2017; Ge et al., 2015; Wernecke and Marsch, 2015; Nilsson et al., 2012; Tatone and Grasselli, 2013; Kim et al., 2015; Kim et al., 2016).

\section{Materials and Methods}

\section{Study Area}

Rock surface located at Istanbul Technical University Ayazaga Campus showed in Fig 1. was selected in order to investigate the relationship between discontinuity, roughness and temperature of rock surface. This rock is the Carboniferous aged Trachia formation of grovak which is one of the basement rocks of Istanbul. Selected object has approximately $3 \mathrm{~m}$ $\mathrm{x} 1 \mathrm{~m}$ dimensions. It is necessary to form sections with a certain interval on the produced model for the surfaces where the rougher region is not clearly visible, to calculate the roughness angles by means of breaking angle (Avsar et al., 2016). For the selected object, what kind of discontinuity is in which region and which roughness of the area is more can be clearly determined by visual interpretation.

\section{Methodology Used}

The methodology used for the study has benefited from photograph data. Applied methodology shown in Fig 2. Consists of two steps as field study and evaluation of the data obtained in field study. Field study covers the measuring the coordinates and temperature of control points and taking the both RGB and thermal photographs. The integration and comparison of the obtained data with each other is the second step. Geodetic measurements and processes were carried out only for the model produced by means of RGB photographs since

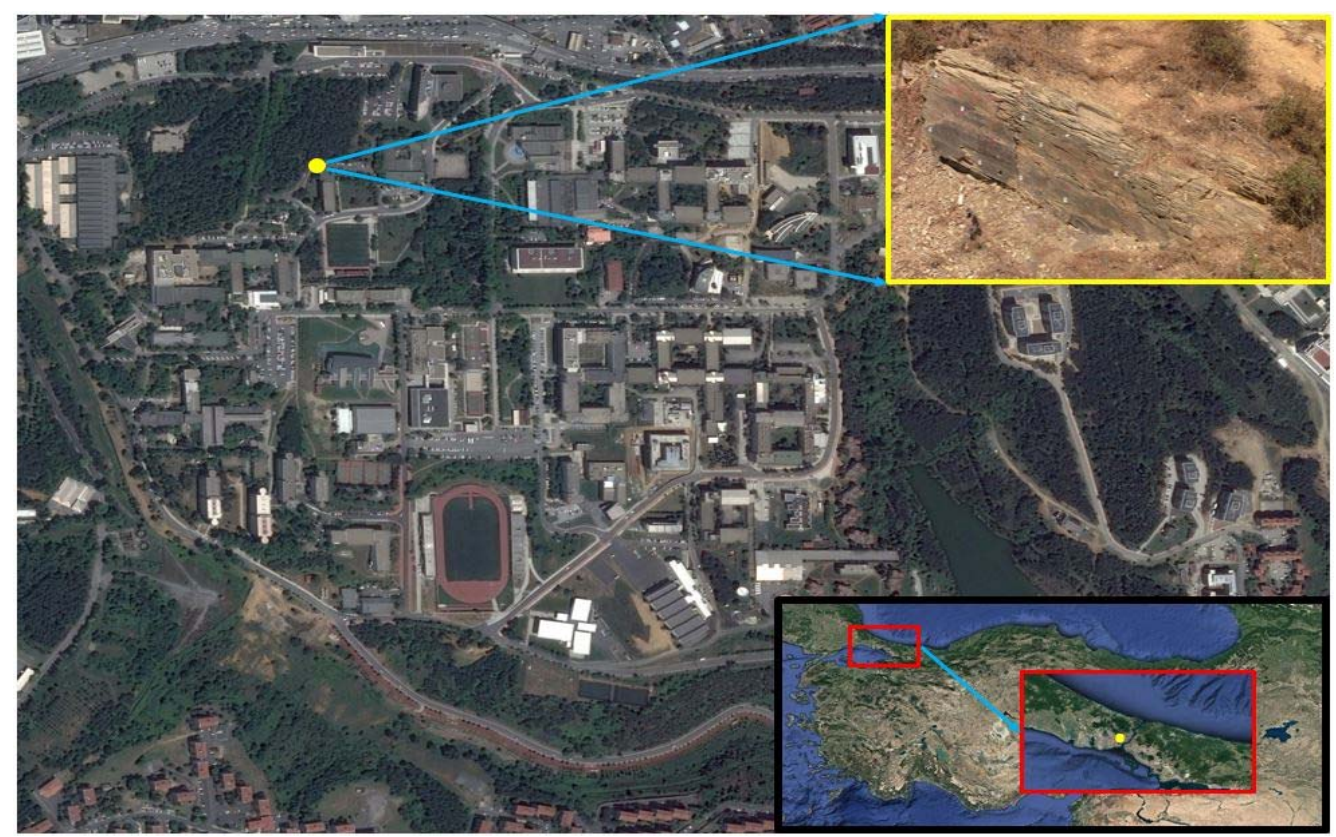

Fig 1. Study area and rock surface investigated

the $3 \mathrm{D}$ object model generated by using thermal photographs already shows the temperature distribution.

Various software were used to evaluate the data obtained during the field study. Agisoft Photoscan software was used for production of
3D object model with RGB photographs while Pix 4d software was used to process thermal images. Cloud Compare which is open source point cloud software was used for editing the point cloud generated after the alignment of the photographs. For the interpolation map which shows the temperature distribution on the 
surface, commercial GIS software ArcGIS was preferred. Geodetic measurements were evaluated in Netcad software. Visual interpretation was made both to compare the different outputs showing the temperature distribution and to determine the rough areas on the object. All the field survey including geodetic measurements and photograph taking operations took about half a day.

Fig 2. Methodology used

The target papers prepared for the control points were placed in a homogeneous distribution on the object as shown in Fig 3. There are target papers on both the rough surfaces, around and fresh areas. Two traverse points in the local coordinate system were used to determine the $3 \mathrm{D}$ coordinates of the control points. The averages of the values obtained from both traverse points were taken into account. RGB photographs were taken by mirrorless Sony a6000 digital camera with 6000 x 4000 maximum resolution and $24 \mathrm{~mm} \times 16$ $\mathrm{mm}$ sensor size, which corresponds to approximately pixel pitch of $4 \mu \mathrm{m}$. This type of mirrorless system sends the sunlight coming towards the lens to the sensor directly. In this way, the image appears both in the electronic viewfinder and on the screen at the same time. A tripod was used to get sufficient sharpness and clarity in the photographs. In order to avoid the vibration that may occur at the time of focusing and exposure, the shutter command was given by using remote control.

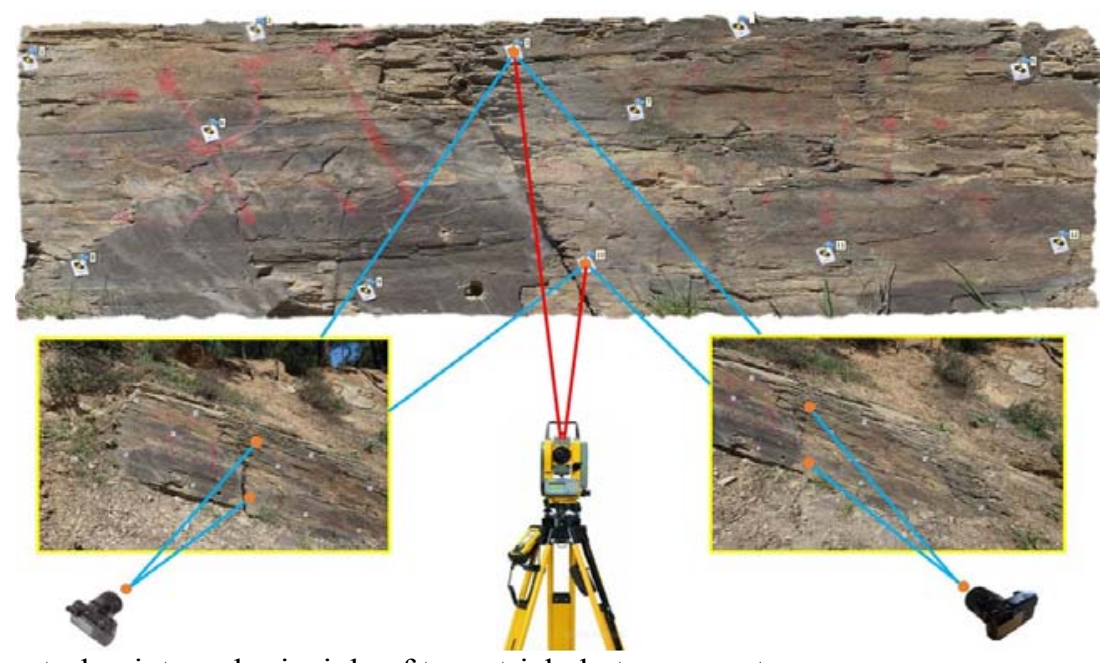

Fig 3.12 control points and principle of terrestrial photogrammetry 
Thermal photographs were obtained by using FLIR thermal camera by controlling with the android software on the phone. It is possible to picture the surface with different colour combinations during the shooting of thermal photographs. Regions warmer than their surroundings are represented by a brighter colour such as white and other regions are darker as shown in Fig 4. The colour combinations representing the temperature differences can be changed to red and blue instead of white and grey later on.

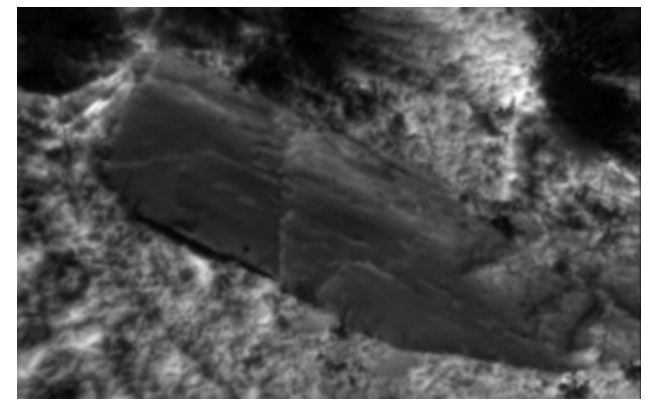

Fig 4. Example of thermal image taken

The temperature values were measured by infrared laser contactless thermometer from the middle of the target papers, which is the part measured by total station, used for the ground control points as shown in Fig 5.
There were 17 control points marked during the field study but only 12 of them on the front face which we thought that they were exposed to sunlight under equal conditions were evaluated. The temperature distribution map is only produced for the front face of the rock surfaces because the incidence angle of the sun rays on the front face of the rock and on the upper side will be different.

Intermediate values were estimated with reference to 12 control points where temperature values were measured on the rock. Intermediate value estimation, also called interpolation, is the process of finding the attributes of the unknown points with the help of attribute values of known points.

This step is based on the basis of geographic information system (GIS). There are three graphical data types in GIS as point, line and polygon. Also, there are three non-graphical data, which is also called attribute data, in GIS as descriptive, quantitative and qualitative. GIS is simply interested in integrating these two data sets. For this application, graphic data is point which has just one coordinate value, no information about length and area and magnitude dependent on the scale. Temperature values of GCPs shown in Table 1 are attribute data used during interpolation.

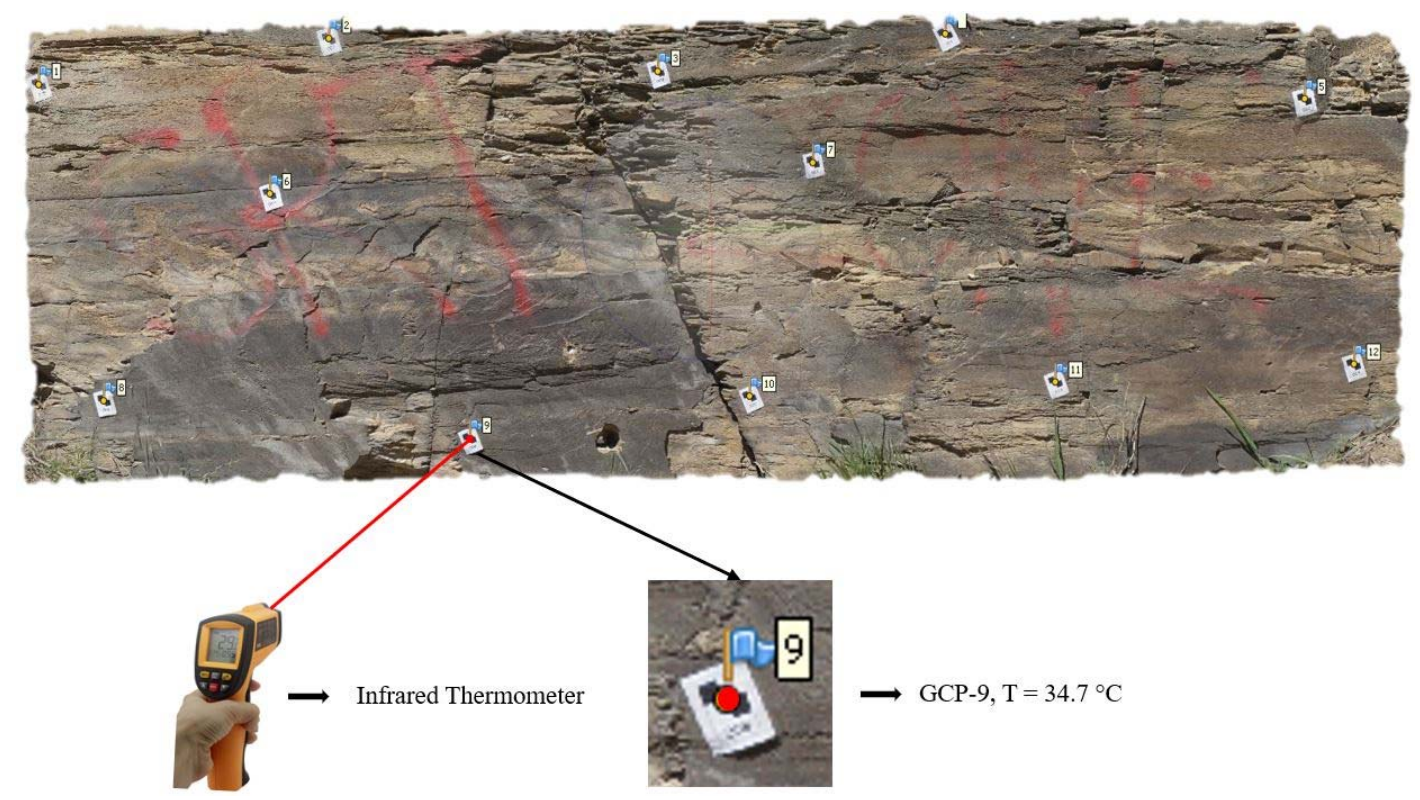

Fig 5. Temperature measurement of GCPs by means of infrared thermometer 
Table 1. Temperature of ground control points

\begin{tabular}{|c|c|}
\hline GCP No & Temperature $\left({ }^{\circ} \mathrm{C}\right)$ \\
\hline 1 & 36.5 \\
\hline 2 & 36.5 \\
\hline 3 & 36.6 \\
\hline 4 & 37.2 \\
\hline 5 & 32.5 \\
\hline 6 & 34.8 \\
\hline 7 & 32.6 \\
\hline 8 & 32 \\
\hline 9 & 34.7 \\
\hline 10 & 36.8 \\
\hline 11 & 34.5 \\
\hline 12 & 34.9 \\
\hline
\end{tabular}

Inverse Distance Weight (IDW) method which is one of the most commonly used interpolation techniques was preferred to produce temperature distribution map. The principle of the IDW method is based on the following formula and Fig 6. given below. The measured values are used to estimate the value of the unmeasured location. The measured value closest to the estimating region has more effect on the predicted value than the other measured values. So, the IDW method assumes that every measured point has a decreasing effect with distance. In other words, IDW is inversely proportional to the distance. While more weight is given to the nearest point, less weight is given to the far point. On the predicted temperature value for $P_{j}$ according to Fig 6., the T3 temperature value of the ground control point 3 has more effect than the T2 temperature value of the ground control point because $d_{3, j}$ distance is smaller than $d_{2, j}$. In the formula below, $P_{j}$ refers to point with unknown attribute while $P_{i}$ refers to point with known attribute. $\mathrm{n}$ has a value of 1 in this application.

$$
P_{j}=\frac{\sum \frac{P_{i}}{d_{i, j}^{n}}}{\sum \frac{1}{d_{i, j}^{n}}}
$$

where

$$
\begin{aligned}
& P_{j}=\text { Estimated value } \\
& P_{\mathrm{i}}=\text { Measured value } \\
& d_{i j}=\text { Distance between measured } \\
& \quad \text { and unmeasured point } \\
& n=\text { Power factor }
\end{aligned}
$$

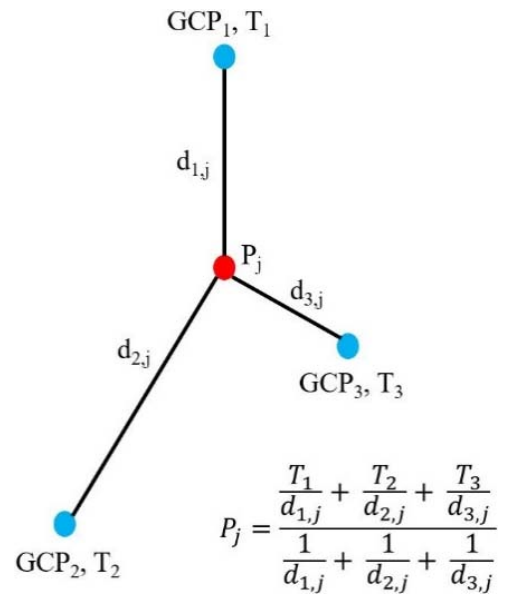

Fig 6. Intermediate value estimation principle of IDW

Discontinuity and roughness regions are shown as 1, 2, 3, and 4 in Fig 7. Generally, there are two shear cracks on a rock surface, which are represented by region 2 and 3 for this surface. These cracks usually develop as a pair by cutting each other between 55 and 60 degrees. The surfaces of the shear cracks are generally smooth and flat as it is in region 2 .

There are tension cracks in region 1 and 4 . Tension cracks develop along the weak zone in the rock body. In the study area, while the compression proceeded inside the rock body, some parts of the rock were squeezed, and a planar shear surface developed in smooth or slickenside roughness profiles along the shear crack plane (region 3 ). On the other hand, a tension was developed as a reaction to the compression inside the rock body and tension cracks were developed along region 1 and 4 . In region 1 , the tension crack exhibits a stepped surface plane with rough discontinuity. In region 4 , the tension crack shows an undulating surface plane with smooth discontinuity. The difference between region 1 and 4 is related with the reaction of the tension to the shear crack developed shown as region 3 in rock body. The tension developing inside the rock body in region 1 was related with the shear developing along the region 3 , and the tension developing in region 4 was related with the hanging wall by region 3 . Roughness develops on these surfaces due to trying to pull off the material by stretching. 


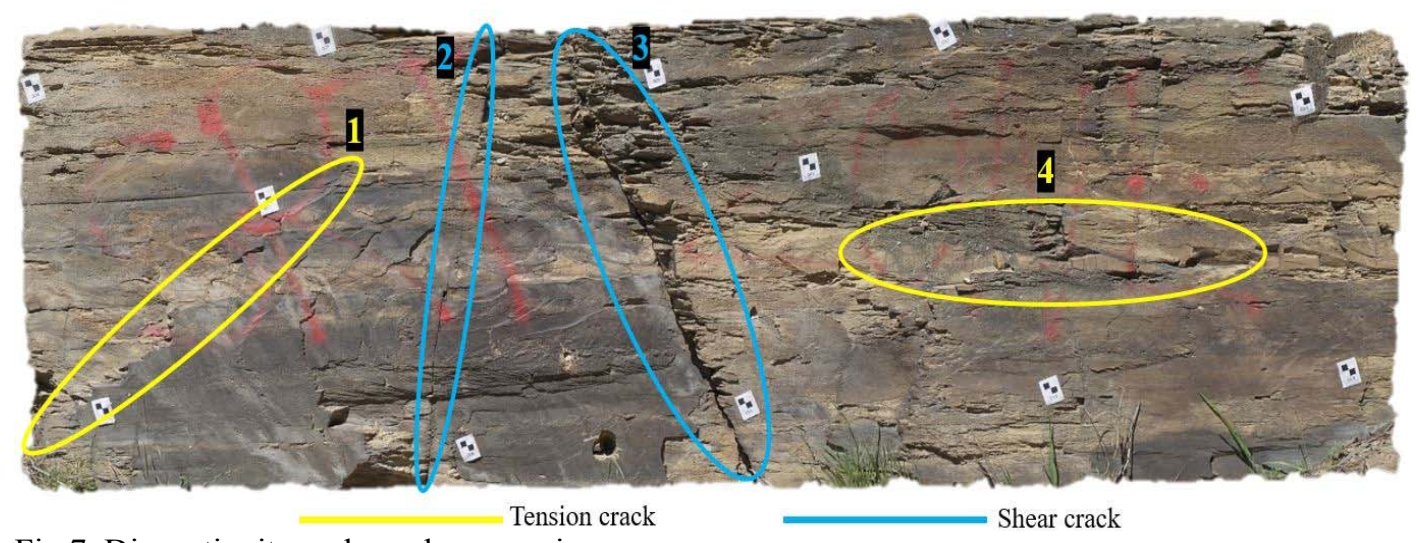

Fig 7. Discontinuity and roughness regions

\section{Results and Conclusions}

Using the 3D coordinate information and temperature values of the 12 control points, a temperature distribution map was produced by the IDW method. The temperature distribution map was overlapped on the 3D surface model later on. Fig. 8 shows the temperature distribution and variations in different regions of the surface and Fig 9 depicts the appearance of the same surface obtained with the help of thermal photographs. The upper part of the rock is seen as the hottest area in Fig. 9 but this area is not included in the comparison and interpretation in terms of making the evaluation on equal conditions because it is exposed differently to the sunlight relative to the front face the rock.

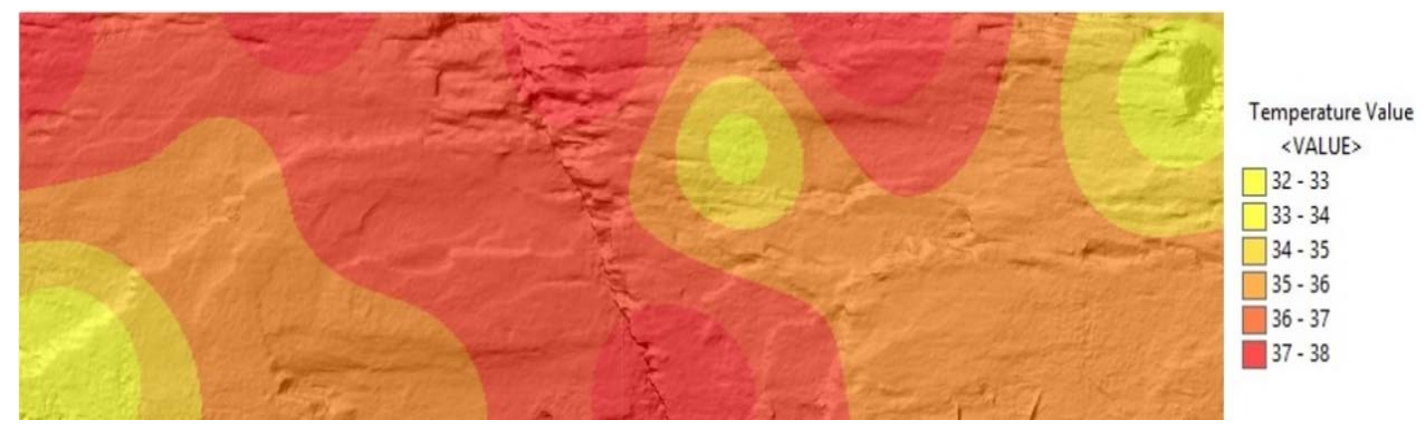

Fig 8. Surface temperature variations

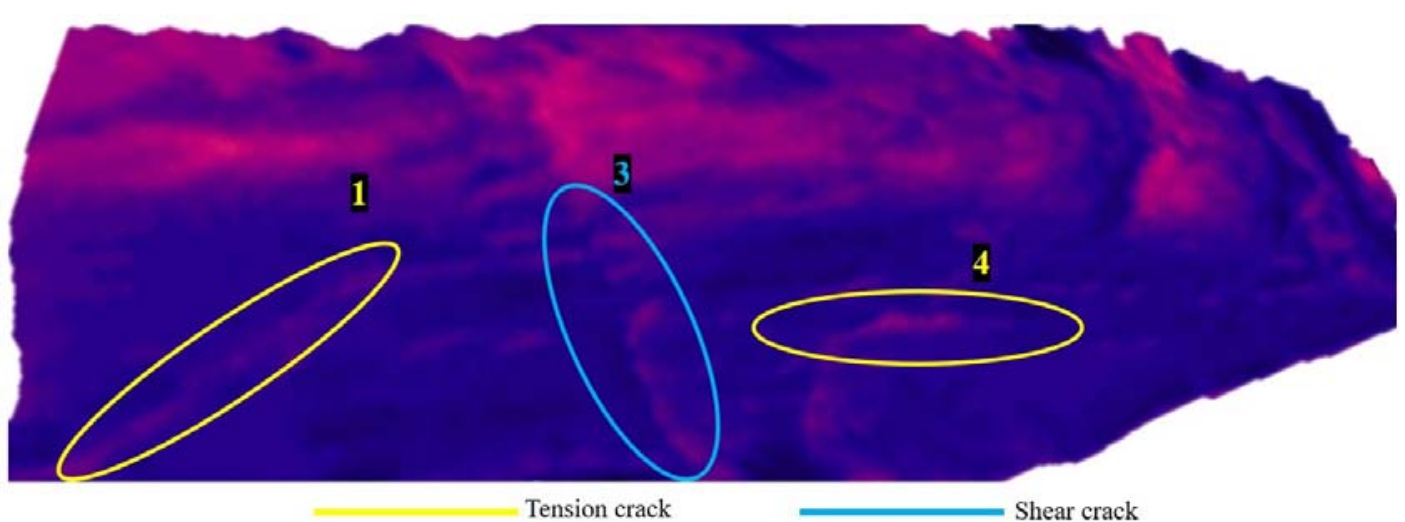

Fig 9. 3D model created by using thermal photographs and roughness regions 
3D model produced by using thermal photographs were accepted as reference data to establish and evaluate relationship between roughness and temperature of the rock surface. The reason of this acceptance is completely realistic reflectance of the surface temperature without intermediate value estimation. When $3 \mathrm{D}$ model showed in Fig 9 is considered, it is observed that regions which have more roughness are warmer than regions with less roughness under equal conditions. It is clear that the colour of the model turns red when regions 1,3 , and 4 are examined. This means that discontinuity areas with roughness absorb more sunlight. Although region 3 is shear crack, there are micro capillaries in this region that prevent the movement of heat by compressing it in the gaps.

Temperature distribution of the surface created by means of temperature of ground control points is partly compatible with thermal model. Region 3 with fracture and micro capillaries is warmer than its surroundings according to map produced by IDW method. It is not possible to say this completely for regions 1 and 4 but the majority of these regions are also warmer than the regions that are less rough than their surroundings.

Used thermal camera may not have the capacity to distinguish all radiometric differences. Also, resolution of thermal photographs is distinctly lower than that of digital RGB photographs. Even if these areas have more temperature value, it cannot be seen differences among themselves in terms of temperature. This is also why the 2 nd region cannot be interpreted in the thermal model efficiently. This region is smaller than the others, making it difficult to interpret with the available resolution. A radiometric thermal camera with higher spatial resolution can give a more detailed and correct temperature variation. But all of this, although the exact location of the line belonging to shear crack in region 2 cannot be determined in the thermal model, the fact that there is no red colour meaning the high temperature values between the region 1 and 3 , which is the possible place where region 2 is, supports the relationship between roughness and temperature. All possible locations where shear in region 2 can be existed are represented by blue.

Both RGB and thermal photographs of the surface were taken afternoon and the temperature of the control points were also measured simultaneously with the photograph shooting process. Therefore, temperature values were between $32^{\circ} \mathrm{C}$ and approximately $37^{\circ} \mathrm{C}$. Measurements to be made at different times of the day, especially when the surface is not exposed to direct sunlight, will also confirm the relationship between surface roughness and temperature.

The reason why the temperature changes on the surface showed by the interpolation map generated by the IDW method does not show similarity in some regions with thermal model may be derived from temperature measurement principle of infrared thermometer. The incident angle of the laser beam to the surface may have caused the measured temperatures to deviate from the actual values.

As a result of the study, it was reached that there is a strong relationship between temperature and roughness. Also, it was seen that obtaining information about rock surface without using thermal camera is possible. It is likely to improve the application in this way in a GIS software which can be used for a study to be made rock surface.

\section{References}

Anbarasan, S., Sakthivel, R. (2017). Digital rock surface mapping of Sittampoondi Anorthosite complex using close range photogrammetry technique. International Journal of Advances in Remote Sensing and GIS, 5(1), 1-9.

Avşar, E.O., Bozkurtoğlu, E., Aydar, U., Şeker, D.Z., Kaya, Ş., Gazioğlu, C. (2016). Determining roughness angle of limestone using optical laser scanner. International Journal of Environment and Geoinformatics (IJEGEO), 3(3), 57-75.

Ge, Y., Tang, H., EZ Eldin, M.A.M., Chen, P., Wang, L., Wang, J. (2015). A description 
for rock joint roughness based on terrestrial laser scanner and image analysis. Scientific Reports, 5(16999), doi: 10.1038/srep16999.

Kim, D.H., Gratchev, I., Balasubramaniam, A. (2015). A photogrammetric approach for stability analysis of weathered rock slopes. Geotechnical and Geological Engineering, 33(3), 443-454.

Kim, D.H., Poropat, G., Gratchev, I., Balasubramaniam, A. (2016). Assessment of the accuracy of close distance photogrammetric JRC data. Rock Mechanics and Rock Engineering, 49(11), 4285-4301.

Nilsson M., Edelbro, C., Sharrock G. (2012). Small scale joint surface roughness evaluation using digital photogrammetry. EUROCK 2012-Rock Engineering and Technology for Sustainable Underground Construction, Stockholm, Sweden.

Ocakoğlu, F. (2014). Genel Jeoloji-1. Osmangazi Üniversitesi, Jeoloji Müh. Böl. Eskişehir.

Özvan, A., Dinçer, İ., Acar, A., Özvan, B. (2014). The effects of discontinuity surface roughness on the shear strength of weathered granite joints. Bulletin of Engineering Geology and the Environment, Vol.73(3):801-813.

Poropat, G.V. (2009). Measurements of Surface Roughness of Rock Discontinuities. Proceedings of the 3rd CANUS Rock Mechanism Symposium, Toronto.

Schultz, R.A., Fossen, H. (2008). Terminology for structural discontinuties. The American Association of Petroleum Geologists (AAPG), 92(7), 853-867.

Tatone B.S.A., Grasselli G. (2012). An investigation of discontinuity roughness scale dependency using high-resolution surface measurements. Rock Mechanics and Rock Engineering, 46(4), 657-681.

Wernecke, C., Marsch, K. (2015). Mapping rock surface roughness with photogrammetry. ISRM Regional Symposium EUROCK-Future Development of Rock Mechanics, Salzburg, Austria. 